\title{
Values and Sex Behavior Attitude among Engineering College Students in Relation to Socio-economic Status
}

\author{
Mr. Ashok B. Patil ${ }^{1 *}$, Dr. G. B. Chaudhari ${ }^{2}$
}

\section{ABSTRACT}

In this era, the value and sex behaviour attitude of the Youth plays important role for the healthy society. The present study is conducted to investigate the values and sex behaviour attitude among engineering college students of Jalgaon city. Kamal Dvivedi and Shagufta Hafeez (1995) Values Scale and Dr Yashvir Singh (2004) Sex Behavior Attitude Inventory is used for the for the sample of 40 students of age group 18-22 years from engineering college of Jalgaon City.

Keywords: Values, Sex Behavior Attitude, Socioeconomic Status and engineering College Students

In this era, the value and sex behavior attitude of the Youth plays important role for the healthy society. Human values depend on family culture and environment. Values play important role in developing attitudes of various approaches. Values are learned, developed and are instrumental for the change in one's life. Individuals acquire experiences. They grow, learn and internalize values as a result of their experiences and experiments in life, through socio-cultural interactions and interpretations. Thus, values are constantly related to the experiences that shape them and test them. They are not, for any one person, so much rigid. As a result of a sufficient amount of influence, certain patterns of evaluating and behaving tend to develop. Certain things are treated as right, desirable or worthy. These tend to become our values.

The sexuality is a basic human experience. Apart from its anatomical, physiological, biochemical and psychological components; it has a personal component which gives it a private meaning and thus, it has been a topic not discussed openly. Sexual attitude refers to how people accept sexual activity for themselves or others. Sexual attitude have been identified as a central concept in the studies of sexuality because it affects many other aspects of sexuality including sexual behavior, sexual fantasies and responses to sexual cues in the environment. The sexual attitudes have

\footnotetext{
${ }^{1}$ Dept of Psychology, M.J.College, Jalgaon, Dist-Jalgaon, India

2 Ph.D.Guide, Dept of Psychology, A.Y.K.K.College, Dhule, India

*Responding Author

Received: March 2, 2017; Revision Received: March 26, 2017; Accepted: March 29, 2017

(C) 2017 Patil A, Chaudhari G; licensee IJIP. This is an Open Access Research distributed under the terms of the Creative Commons Attribution License (www.creativecommons.org/licenses/by/2.0), which permits unrestricted use, distribution, and reproduction in any Medium, provided the original work is properly cited.
} 
changed in the last century. Previously sex was mainly for reproductive purposes and emphasis on pleasure was not as important. Sexual attitudes have become more permissive over the recent decades. Many youngsters are engaging in premarital sexual practices with the changing times. Now-a-days, the news-media reports violent sexual assaults everyday and many go unreported. Rapes and murders do not surprise us anymore. It is important to investigate the psychological and social reasons behind impulsive, aggressive sexual behaviors. Both educated and uneducated people hold similar views of sexual behaviors. It is misunderstood by both the classes. Their minds occupied with prejudices. Human values have becoming disintegrated. In such a situation it becomes necessary to study the problem systematically and scientifically.

\section{Significance of the Problem}

Though students know what patriotism is, it should be studied whether it is inculcated among them or not. Many of them are away from the feeling of sacrifice, devotion and pride for the nations. The present world is very competitive and every moment we are facing some opportunities and threats in our lives. The world is coming closer by technology and various opportunities are available now. Some of the students are aware of it and therefore they know the real value of time. They know time is worth and once it is spent; we cannot get it back. Therefore they are having good approach for the honesty, punctuality. As there are many religions, castes and communities in India; college students are aware of it. They know about our traditions culture and history of freedom. They have understanding about having respect of other religions in short values gave the shape of the personality of an individual. The term value in the present study means a pattern of generalized attitudes with real independent existence indicating the desirability of behavior in terms of social and psychological needs.

\section{Basic Concept in the Present Study}

Value: Value is systematically loaded word: The term value has different connotations; depending on the context in which is used. Value means principles, ideals, standards, morals, ethics and worth. "a norm or standard of desirability within a culture and interiorized within the individual through interaction with his environment."

Sex Behavior attitude: These are a person's beliefs about sexuality shown by a person's behavior and are based on views.

Engineering Students: Students studying in under graduate level in engineering colleges of Jalgaon city in the year 2015-16.

Socioeconomic Status: - Socioeconomic status is commonly conceptualized as the social standing or class of an individual or group. It is often measured as a combination of education, income and occupation. 


\section{REVIEW OF LITERATURE}

Rastogi (1974) undertook a comparative study to find out the value system of students belonging to different professional courses i.e. Engineering, Medicines, Pharmacy and Draftsmanship. The investigator found that all the four groups were high in science values and low in aesthetic values.

Agrawal (1959) designed a study to explore the value systems and dimensions of students in U.P. The data was collected from the students of six faculties, namely arts, science, law, commerce, engineering and medicine of Lucknow and Roorkee Universities. The major findings are following:

1. The commonly liked ways of life are those having emphasis on self restraint, moderation and integration of action, enjoyment and contemplation.

2. The conceived values of an individual largely taken into account the cultural pattern of the requirements of the social system.

3. In religious values and temporal change, much emphasis is placed on human effort, and fate is also favored suggesting the dependence and adherence to his culture.

4. In value preference, the value items preferred were qualities of friendship, worthy aim and aspiration.

5. In case of social values, subjection to parental authority is not very rigid and students have a congenial outlook towards the outer world.

Nisar (2000) conducted a comparative study of value profile among engineers, doctors, and teachers. The sample consisted of 210 professionals from certain departments of A.M.U. Aligarh. It has been observed that teachers and doctors are more inclined towards social, knowledge, aesthetic and family prestige values in comparison to engineers. Engineers are inclined towards economic and democratic values. Teachers are more inclined towards religious values than doctors and engineers. Doctors are more concerned with health value than the engineers and teachers.

Erin Cross \& Rustain Morga ( 2003-4)The sexual attitudes and behaviors of college students have changed throughout the recent history, as has sex education. What has been created is a generation of college students who are more knowledgeable about sexual positions and protection than previous generations of students. This has resulted in a generation who engages in sexual experimentation earlier than ever before, dangerously mixes alcohol and sex, and can access sex or sex information 24 hours a day with just the click of a mouse. Consequently, sex educators are forced to find new ways to reach this population of students. Inundating students with information during their required classes, utilizing multimedia approaches, and increasing cultural competency among heath educators are all innovative ways that educators are successfully bringing sex education to the college campus. However, the dangerous sexual

(C) The International Journal of Indian Psychology, ISSN 2348-5396 (e) | ISSN: 2349-3429 (p) | 125 


\section{Values and Sex Behavior Attitude among Engineering College Students in Relation to Socio-economic Status}

behaviors that college students engage in are not likely to go away over night; educators must continue to be diligent adults. and creative in their efforts to educate young.

Busisiwe Kopele and Almon Shumba (2011) The study was conducted at the Alice Campus of the University of Fort Hare using a target population of 362 second year Psychology students. In this study, a purposive sample of 30 students (10 male, 20 female; aged 17 - 30 years) was selected from the population. However, 3 (10 percent) participants decided to pull out of the study at the last minute. As such, the research report was based on a total of 27 participants. The final sample comprised of 9 (33.3 percent) male and 18 (66.7 percent) female participants. The findings of this study are an eye-opener on the sexual behaviors and attitudes of students towards safe sex in universities. The findings have revealed that most students engage in unprotected sex and that some students fear taking an HIV test. Since young people are the future leaders, there is need to educate them about the consequences of unprotected sex. Our communities need to stand together and educate the young people about the dangers of having multiple partners and unprotected sex.

\section{Aim of the Study}

Study of the Values and Sex Behavior Attitude among Engineering College Students, in Relation to Socioeconomic Status.

\section{Objectives of the study}

1. To study the difference between Aesthetic, economic, moral, political, religious, social and theoretical values of Male and Female students.

2. To study the difference between aesthetic, economic, moral, political, religious, social and theoretical values of high and low socioeconomic status among engineering college students.

3. To study the permissiveness and restrictiveness of sex behavior attitude of male and female students.

4. To study the permissiveness and restrictiveness of sex behavior attitude of engineering college students having high and low socioeconomic status.

\section{Hypotheses of Research}

1. There is no significant difference between aesthetic, economic, moral, political, religious, social and theoretical values of male and female students.

2. There is no significant difference between different aspects of Values of engineering college students having high and low socioeconomic status.

3. There is no significant difference in permissiveness and restrictiveness of sex behavior attitude between male and female Engineering college students.

4. There is no significant difference in permissiveness and restrictiveness of sex behavior attitude between engineering college students having high and low socioeconomic status.

(c) The International Journal of Indian Psychology, ISSN 2348-5396 (e)| ISSN: 2349-3429 (p) | 126 


\section{Variables}

1. Independent Variables

A- Science College Students.

B- Gender: Male and Female.

C- Socioeconomic Status High and Low.

\section{Dependent Variables}

A) Scores on Values Scale

B) Scores on Sex Behavior attitude Inventory.

\section{METHODOLOGY}

\section{Sample}

Simple random sampling method is used. The sample of 40 students studying in Engineering College in Jalgaon City is taken.

\section{Experimental Design}

In the present research, $2 \times 2$ factorial design is used.

\begin{tabular}{|l|l|l|l|}
\hline \multicolumn{4}{|l|}{ Faculty } \\
\hline & \multicolumn{2}{|l|}{ Engineering College } & \\
\hline Gender & High SES & Low SES & Total \\
\hline Boys & $\mathbf{1 0}$ & $\mathbf{1 0}$ & $\mathbf{2 0}$ \\
\hline Girls & $\mathbf{1 0}$ & $\mathbf{1 0}$ & $\mathbf{2 0}$ \\
\hline Total & $\mathbf{2 0}$ & $\mathbf{2 0}$ & $\mathbf{4 0}$ \\
\hline
\end{tabular}

\section{Tools of the Study}

Values Scale (1995): This test constructed by Kamal Dvivedi and Shagufta Hafeez. In this test consists of 30 items. This test has split half reliability of .87 and validity is .55 which is age group wise Validity is .45 .

Sex Behavior Attitude Inventory (2004): This test constructed by Yashvir Singh in this test consists of 40 items in two dimensions is permissiveness and restrictiveness. This test has split half reliability which is .57 Validity is .35 .

\section{RESULT AND DISCUSSION}

In this part investigator has explained the result related to statistical analysis and hypothesis

\section{Hypothesis no -1}

There is no significant mean difference among aesthetic, economic, moral, political, religious, social and theoretical values of boys and girls in engineering college students. 
Values and Sex Behavior Attitude among Engineering College Students in Relation to Socio-economic Status

Table No.1

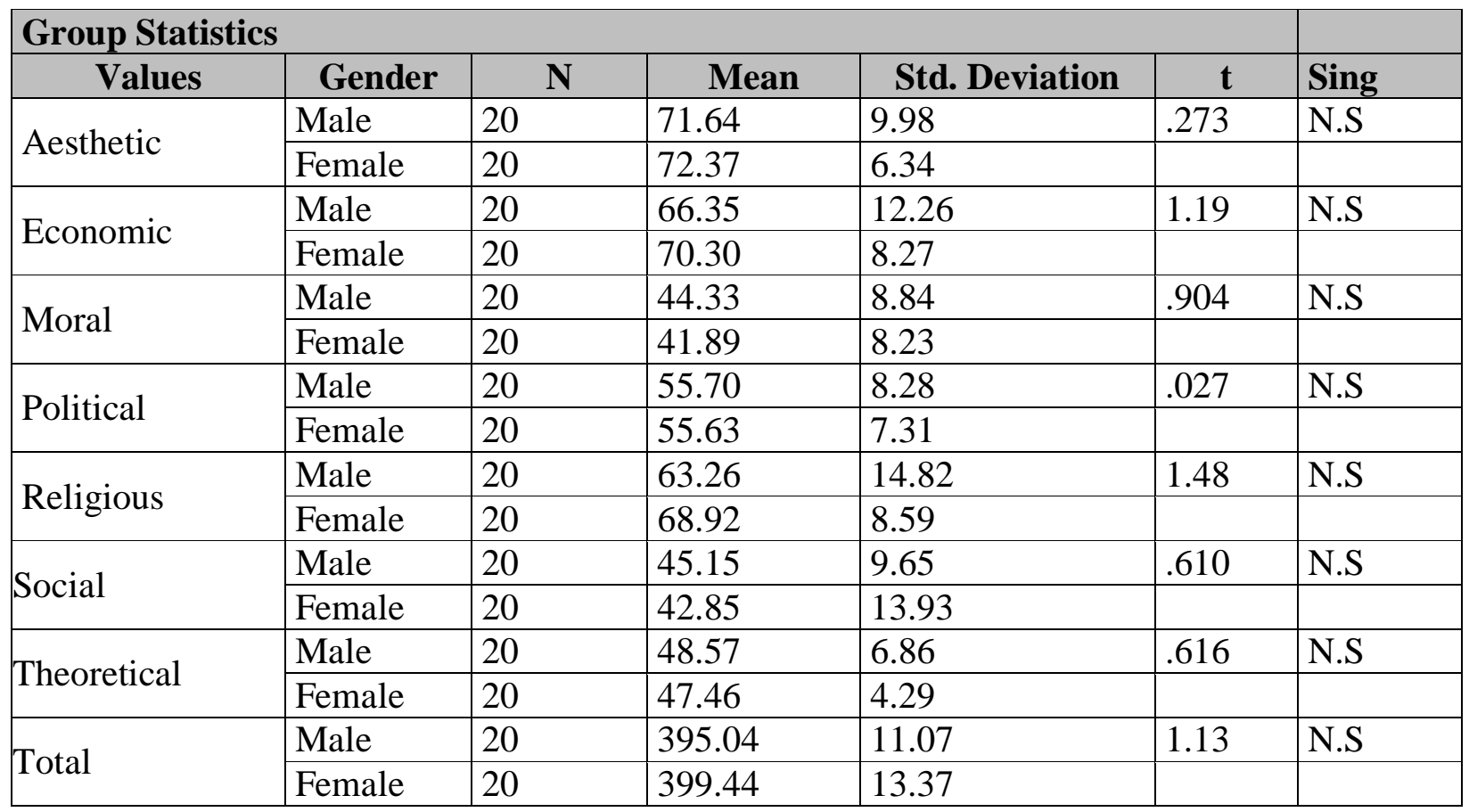

Table value $0.05=2.02, \quad 0.01=2.72$

1. The results of the table No. 1 shows that engineering college Male and Female students for Values factor no. 01 Aesthetic value are listed above The researcher have found that the mean value for male students who showed Aesthetic value was 71.64 and SD is 9.98, Similarly the mean value for female students who showed Aesthetic value is 72.37 and SD is 6.34. The calculated ' $t$ ' value is .273. It is not significant. It indicates that there is no significant difference on engineering college Male and Female students in their Aesthetic value.

2. The results of the table No. 1 shows that engineering college Male and Female students for Values factor no. 02 Economic value are listed above The researcher have found that the mean value for male students who showed Economic value was 66.36 and SD is 12.26 Economic value, Similarly the mean value for female students who showed Economic value is 70.31 and $S D$ is 8.28 . The calculated ' $t$ ' value is 1.19 . It is not significant. It indicates that there is no significant difference on engineering college Male and Female students in their Economic value.

3. The results of the table No. 1 shows that engineering college Male and Female students for Values factor no. 03 Moral value are listed above The researcher have found that the mean value for male students who showed Moral value was 44.33 and SD is 8.85, Similarly the mean value for female students who showed Moral value is 41.89 and SD is 8.23. The calculated ' $t$ ' value is .994. It is not significant. It indicates that there is no significant difference on engineering college Male and Female students in their Moral value.

(c) The International Journal of Indian Psychology, ISSN 2348-5396 (e)| ISSN: 2349-3429 (p) | 128 
Values and Sex Behavior Attitude among Engineering College Students in Relation to Socio-economic Status

4. The results of the table No. 1 shows that engineering college Male and Female students for Values factor no. 04 Political value are listed above The researcher have found that the mean value for male students who showed Political value was 55.70 and SD is 8.28, Similarly the mean value for female students who showed Political value is 55.63 and SD is 7.31. The calculated ' $t$ ' value is .027. It is not significant. It indicates that there is no significant difference on engineering college Male and Female students in their Political value.

5. The results of the table No. 1 shows that engineering college Male and Female students for Values factor no. 05 Religious value are listed above The researcher have found that the mean value for male students who showed Religious value was 63.26 and SD is 14.82, Similarly the mean value for female students who showed Religious value is 68.92 and SD is 8.59. The calculated ' $t$ ' value is 1.48 . It is not significant. It indicates that there is no significant difference on engineering college Male and Female students in their Religious value.

6. The results of the table No. 1 shows that engineering college Male and Female students for Values factor no. 06 Social value are listed above The researcher have found that the mean value for male students who showed Social value was 45.17 and SD is 9.65 , Similarly the mean value for female students who showed Social value is 42.85 and SD is 13.93. The calculated ' $t$ ' value is .610. It is not significant. It indicates that there is no significant difference on engineering college Male and Female students in their Social value.

7. The results of the table No. 1 shows that engineering college Male and Female students for Values factor no. 07 Theoretical value are listed above The researcher have found that the mean value for male students who showed Theoretical value was 48.57and SD is 6.86, Similarly the mean value for female students who showed Theoretical value is 47.46 and SD is 4.29. The calculated 't' value is .616. It is not significant. It indicates that there is no significant difference on engineering college Male and Female students in their Theoretical value.

8. The results of the table No. 1 shows that engineering college Male and Female students for Values are listed above The researcher have found that the mean value for male students who showed value was 395.04 and SD is 11.07 , Similarly the mean value for female students who showed value is 399.44 and SD is 13.37. The calculated ' $t$ ' value is 1.13. It is not significant. It indicates that there is no significant difference on engineering college Male and Female students in their values.

\section{Hypothesis no -2}

There is no significant mean difference among aesthetic economic, moral, Political, religious, social and theoretical values of high and low socioeconomic status in engineering college students. 
Values and Sex Behavior Attitude among Engineering College Students in Relation to Socio-economic Status

Table No.2

\begin{tabular}{|c|c|c|c|c|c|c|}
\hline \multicolumn{6}{|c|}{ Group Statistics } & \multirow[b]{2}{*}{ Sing } \\
\hline & SES & $\mathbf{N}$ & Mean & Std. Deviation & $\mathbf{t}$ & \\
\hline \multirow{2}{*}{ Aesthetic } & High & 20 & 72.18 & 7.02 & \multirow{2}{*}{.125} & \multirow{2}{*}{ N.S } \\
\hline & Low & 20 & 71.85 & 9.53 & & \\
\hline \multirow{2}{*}{ Economic } & High & 20 & 68.39 & 11.39 & \multirow{2}{*}{.032} & \multirow{2}{*}{ N.S } \\
\hline & Low & 20 & 68.28 & 9.86 & & \\
\hline \multirow{2}{*}{ Moral } & High & 20 & 42.74 & 8.87 & \multirow{2}{*}{.273} & \multirow{2}{*}{ N.S } \\
\hline & Low & 20 & 43.48 & 8.38 & & \\
\hline \multirow{2}{*}{ Political } & High & 20 & 56.07 & 8.11 & \multirow{2}{*}{.327} & \multirow{2}{*}{ N.S } \\
\hline & Low & 20 & 55.27 & 7.47 & & \\
\hline \multirow{2}{*}{ Religious } & High & 20 & 66.16 & 10.83 & \multirow{2}{*}{.036} & \multirow{2}{*}{ N.S } \\
\hline & Low & 20 & 66.02 & 13.90 & & \\
\hline \multirow{2}{*}{ Social } & High & 20 & 41.88 & 9.50 & \multirow{2}{*}{1.14} & \multirow{2}{*}{ N.S } \\
\hline & Low & 20 & 46.14 & 13.79 & & \\
\hline \multirow{2}{*}{ Theoretical } & High & 20 & 48.35 & 6.00 & \multirow{2}{*}{.371} & \multirow{2}{*}{ N.S } \\
\hline & Low & 20 & 47.68 & 5.46 & & \\
\hline \multirow{2}{*}{ Total } & High & 20 & 395.76 & 9.48 & \multirow{2}{*}{.75} & \multirow{2}{*}{ N.S } \\
\hline & Low & 20 & 398.71 & 14.72 & & \\
\hline
\end{tabular}

Table value $0.05=2.02, \quad 0.01=2.72$

1. The results of the table No. 2 shows that engineering college high SES and low SES students for Values factor no. 01 Aesthetic value are listed above The researcher have found that the mean value for high SES students who showed Aesthetic value was 72.18 and SD is 7.02, Similarly the mean value for low SES students who showed Aesthetic value is 71.85 and SD is 9.53 . The calculated' $t$ ' value is .125. It is not significant. It indicates that there is no significant difference on engineering college high SES and low SES students in their Aesthetic value.

2. The results of the table No. 2 shows that engineering college high SES and low SES students for Values factor no. 02 Economic value are listed above The researcher have found that the mean value for high SES students who showed Economic value was 68.39 and SD is 11.39 Economic, Similarly the mean value for low SES students who showed Economic value is 68.28 and SD is 9.86. The calculated't' value is .032. It is not significant. It indicates that there is no significant difference on engineering college high SES and low SES students in their Economic value.

3. The results of the table No. 2 shows that engineering college high SES and low SES students for Values factor no. 03 Moral value are listed above The researcher have found that the mean value for high SES students who showed Moral value was 42.74 and SD is 8.87, Similarly the mean value for low SES students who showed Moral value is 43.48 and SD is 8.38. The calculated' $t$ ' value is .273. It is not significant. It indicates that there is no

(C) The International Journal of Indian Psychology, ISSN 2348-5396 (e)| ISSN: 2349-3429 (p) | 130 
Values and Sex Behavior Attitude among Engineering College Students in Relation to Socio-economic Status

significant difference on engineering college Male and Female students in their Moral value.

4. The results of the table No. 2 shows that engineering college high SES and low SES students for Values factor no. 04 Political value are listed above The researcher have found that the mean value for high SES students who showed Political value was 56.07 and SD is 8.11, Similarly the mean value for low SES students who showed Political value is 55.27 and SD is 7.47. The calculated 't' value is.327. It is not significant. It indicates that there is no significant difference on engineering college high SES and low SES students in their Political value.

5. The results of the table No. 2 shows that engineering college high SES and low SES students for Values factor no. 05 Religious value are listed above The researcher have found that the mean value for high SES students who showed Religious value was 66.16 and SD is 10.82, Similarly the mean value for low SES students who showed Religious value is 66.01 and SD is 13.90 . The calculated' $t$ ' value is .036 . It is not significant. It indicates that there is no significant difference on engineering college high SES and low SES students in their Religious value.

6. The results of the table No. 2 shows that engineering college high SES and low SES students for Values factor no. 06 Social value are listed above The researcher have found that the mean value for high SES students who showed Social value was 41.88 and SD is 9.50, Similarly the mean value for low SES students who showed Social value is 46.14 and $\mathrm{SD}$ is 13.79. The calculated ' $t$ ' value is 1.14. It is not significant. It indicates that there is no significant difference on engineering college high SES and low SES students in their Social value.

7. The results of the table No. 2 shows that engineering college high SES and low SES students for Values factor no. 07 Theoretical value are listed above The researcher have found that the mean value for high SES students who showed Theoretical value was 48.35 and SD is 6.00, Similarly the mean value for low SES students who showed Theoretical value is 47.68 and SD is 5.46 . The calculated ' $t$ ' value is .371. It is not significant. It indicates that there is no significant difference on engineering college high SES and low SES students in their Theoretical value.

8. The results of the table No. 2 shows that engineering college high SES and low SES students for Values factor no. 08 total value are listed above The researcher have found that the mean value for high SES students who showed total value was 395.76 and SD is 9.48, Similarly the mean value for low SES students who showed Social value is 398.71 and SD is 14.72. The calculated' value is .75 . It is not significant. It indicates that there is no significant difference on engineering college high SES and low SES students in their total value. 
Values and Sex Behavior Attitude among Engineering College Students in Relation to Socio-economic Status

\section{Hypothesis no -3}

There is no significant difference in Restrictiveness and permissiveness of sex behavior attitude between boys and girls in engineering college students.

Table No 3

\begin{tabular}{|c|c|c|c|c|c|c|}
\hline \multicolumn{6}{|c|}{ Group Statistics } & \multirow[b]{2}{*}{ Sing } \\
\hline & Gender & $\mathbf{N}$ & Mean & Std. Deviation & $\mathbf{t}$ & \\
\hline \multirow{2}{*}{ Restrictiveness } & Male & 20 & 30.15 & 3.25 & \multirow{2}{*}{1.322} & \multirow{2}{*}{ N.S } \\
\hline & Female & 20 & 31.35 & 2.43 & & \\
\hline \multirow{2}{*}{ Permissiveness } & Male & 20 & 29.70 & 2.11 & \multirow{2}{*}{.932} & \multirow{2}{*}{ N.S } \\
\hline & Female & 20 & 29.00 & 2.66 & & \\
\hline
\end{tabular}

Table value $0.05=2.02, \quad 0.01=2.72$

The results of the table No. 3 shows that engineering college Male and Female students for sex behavior attitude factor no. 01 Restrictiveness are listed above The researcher have found that the mean value for male students who showed Restrictiveness was 30.15 and SD is 3.25, Similarly the mean value for female students who showed Restrictiveness is 31.35 and SD is 2.43. The calculated ' $t$ ' value is 1.32. It is not significant. It indicates that there is no significant difference on engineering college Male and Female students in their Restrictiveness of sex behavior attitude.

The results of the table No. 3 shows that engineering college Male and Female students for sex behavior attitude factor no. 02 Permissiveness are listed above The researcher have found that the mean value for male students who showed Permissiveness was 29.70 and SD is 2.11, Similarly the mean value for female students who showed Permissiveness is 29.00 and SD is 2.66. The calculated 't' value is .932. It is not significant. It indicates that there is no significant difference on engineering college Male and Female students in their Permissiveness of sex behavior attitude.

\section{Hypothesis no -4}

There is no significant difference in permissiveness and Restrictiveness of sex behavior attitude between High and Low socioeconomic status in engineering college students.

Table No.4

\begin{tabular}{|c|c|c|c|c|c|c|}
\hline \multicolumn{6}{|c|}{ Group Statistics } & \multirow[b]{2}{*}{ Sing } \\
\hline & SES & $\mathbf{N}$ & Mean & Std. Deviation & $\mathbf{t}$ & \\
\hline \multirow{2}{*}{ Restrictiveness } & High & 20 & 31.45 & 2.61 & \multirow{2}{*}{1.56} & \multirow{2}{*}{ N.S } \\
\hline & Low & 20 & 30.05 & 3.06 & & \\
\hline \multirow{2}{*}{ Permissiveness } & High & 20 & 28.90 & 2.61 & \multirow{2}{*}{1.21} & \multirow{2}{*}{ N.S } \\
\hline & Low & 20 & 29.80 & 2.07 & & \\
\hline
\end{tabular}

Table value $0.05=2.02, \quad 0.01=2.72$

(c) The International Journal of Indian Psychology, ISSN 2348-5396 (e)| ISSN: 2349-3429 (p) | 132 
The results of the table No. 4 shows that engineering college High and Low socioeconomic status students for sex behavior attitude factor no. 01 Restrictiveness are listed above The researcher have found that the mean value for high SES students who showed Restrictiveness was 31.45 and SD is 2.61, Similarly the mean value for low SES students who showed Restrictiveness is 30.05 and SD is 3.06. The calculated ' $t$ ' value is 1.56. It is not significant. It indicates that there is no significant difference on engineering college Male and Female students in their Restrictiveness of sex behavior attitude.

The results of the table No. 4 shows that engineering college High and Low socioeconomic status students for sex behavior attitude factor no. 02 Permissiveness are listed above The researcher have found that the mean value for high SES students who showed Permissiveness was 28.90 and SD is 2.61, Similarly the mean value for low SES students who showed Permissiveness is 29.80 and SD is 2.07. The calculated ' $t$ ' value is 1.21 . It is not significant. It indicates that there is no significant difference on engineering college High and Low socio

\section{CONCLUSION}

1. There is no significant mean difference among aesthetic, economic, moral, political, religious, social and theoretical values of male and female students.

2. There is no significant mean difference among aesthetic, economic, moral, political, religious, social and theoretical values of engineering college students having high and low socioeconomic status.

3. There is no significant difference in permissiveness and restrictiveness of sex behavior attitude between male and female students.

4. There is no significant difference in permissiveness and restrictiveness of sex behavior attitude between engineering college students having high and low socioeconomic status.

\section{Acknowledgments}

The author appreciates all those who participated in the study and helped to facilitate the research process.

Conflict of Interests: The author declared no conflict of interests.

\section{REFERENCES}

Agrawal, V. (1959). Value System and Dimensions of University students of U.P., Ph.D.Thesis. A Survey of Research in Education, 99.

Manav, R.N. (1981). A Study of Attitudes, Self Concepts and Values of Professional and NonProfessional College Students and Relationship of these Variables with their Achievements, Ph.D.Thesis. Third Survey of Research in Education, 375. 
Values and Sex Behavior Attitude among Engineering College Students in Relation to Socio-economic Status

Nisar, Z. (2000). Comparative Study of Value Profile among Engineers, Doctors and Teachers. M.Ed. Dissertation, A.M.U., Aligarh. Economic status students in their Permissiveness of sex behavior attitude.

Erin Cross \& Rustain Morgan (2003-4) Sexual Attitudes and Behaviors of College Students Sexual Attitudes and Behaviors of College Students Erin Cross ('03) currently works as a Program Advisor in Residence Life at Colorado State University and is a graduate .

Busisiwe Kopele and Almon Shumba (2011) Sexual Behaviours and Attitudes towards Safer Sex of Psychology Students at a South African University Campus Anthropologist, 13(4): 257-264 (2011)

How to cite this article: Patil A, Chaudhari G (2017), Values and Sex Behavior Attitude among Engineering College Students in Relation to Socio-economic Status, International Journal of Indian Psychology, Volume 4, Issue 2, No. 95, ISSN:2348-5396 (e), ISSN:2349-3429 (p), DIP:18.01.173/20170402, ISBN:978-1-365-84231-3

(c) The International Journal of Indian Psychology, ISSN 2348-5396 (e)| ISSN: 2349-3429 (p) | 134 